\title{
A BIOMECHANICAL STUDY OF THE EFFECTS OF GROWTH HORMONE IN EXPERIMENTAL FRACTURE HEALING
}

\author{
M. D. NORTHMORE-BALL, M. R. WOOD, B. F. MEGGITT \\ From Addenbrooke's Hospital, Cambridge
}

\begin{abstract}
In 65 mature Wistar rats a Kirschner wire was introduced into the medullary cavity of each femur. A closed transverse mid-shaft fracture of one femur was produced by a three-point bending technique. Subsequently the mechanical characteristics of the healing fracture, including the torque and angle of twist required to take the callus to its yield point and to ultimate failure, were compared with those for the opposite femur of each rat. Controls were killed in groups at two, three, four, five and seven weeks. Test animals were given bovine growth hormone in a daily dose of five milligrams before being killed in groups at two, three and four weeks. A significant increase in torque index was found in the two-week group of test animals but not in subsequent groups. No evidence was found that growth hormone given alone could produce an overall shortening of the healing time in fresh fractures.
\end{abstract}

The large number of seriously injured patients now requiring treatment, and the long-term disability associated with skeletal injury, underline the socioeconomic importance of attempts to expedite healing. Among methods using humoral agents, growth hormone has been used clinically as an adjuvant in treatment of fractures (Laborit et al. 1953; Cordebar and Guilleman 1956; Koskinen 1963; Koskinen et al. 1977; Lindholm et al. 1977). Although most of these authors described a beneficial effect on the healing of long bones in humans, especially in cases of delayed union or non-union, there has been little overall uniformity about the experimental basis for such treatment.

Shepanek (1953) gave growth hormone intramuscularly to male white mice with experimental fractures, and healing was assessed histologically and by testing "mechanical strength", the exact nature of which was not stated. He concluded that growth hormone did not interfere with callus formation but did not speed its maturity; in combination with adrenocorticotropic hormone (ACTH), growth hormone actually inhibited healing. Koskinen (1959), using white female rats with fractures of the tibia which had been produced by closed digital osteoclasis, gave them 30 tibia units of somatotrophin intramuscularly daily. His testing was by radiography, histology and autoradiography. He found striking effects. Callus was produced more rapidly and the cartilage in the callus showed increased osteogenesis, results similar to the well-established effects of growth hormone on epiphysial plate cartilage. Clinical stability was achieved one week earlier than in controls, and radiographs showed an early closure of the gap between the fragments. These effects were partially confirmed by Udupa and Gupta (1965). They gave 0.1 milligram of bovine growth hormone on alternate days intramuscularly to growing albino rats with a closed digital fracture of the humerus, and assessed healing by histological and histochemical methods and by testing tensile strength at weekly intervals. They found increased osteogenesis, but no effect on strength, and quoted figures which showed that the treated fractures were actually weaker in the early and middle stages of healing. Statistical analysis, however, was not given. Wray and Goldstein (1966) gave 50 micrograms of bovine growth hormone daily for 28 days to hypophysectomised rats, with suitable controls, and found a statistically significant reduction in the strength of the healing fracture, a result which they attributed to experimental error or to chance. Harris, Bean and Banks (1975) gave an unspecified type of growth hormone in a dose of 0.46 international units per kilogram body weight intramuscularly daily to New Zealand white rabbits with a closed osteoclasis of the tibia, and found no effect on the tensile strength of the healing fracture. In contrast, Zadek and Robinson (1961), who gave bovine growth hormone in a dose of one milligram per kilogram three times a week to adult dogs with closed epiphyses, found healing of a three-centimetre radial defect only in those animals given the hormone and not in controls and concluded that there was an eventual possibility of such a substance being used clinically to increase the rate of bone healing.

It will be noted that several different types of experimental animal have been used, with growth

M. D. Northmore-Ball, FRCS, Senior Orthopaedic Registrar M. R. Wood, FRCS, Senior Orthopaedic Registrar

B. F. Meggitt, FRCS, Consultant Orthopaedic Surgeon

Addenbrooke's Hospital. Hills Road.

Requests for reprints should be sent to Mr M. D. Northmore-Ball. 


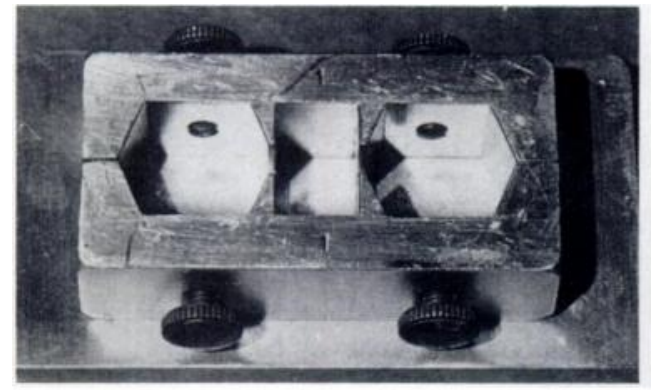

Fig. 1

Figure 1 -Specially designed jig for mounting bones. Figure 2 - The torsional testing machine.

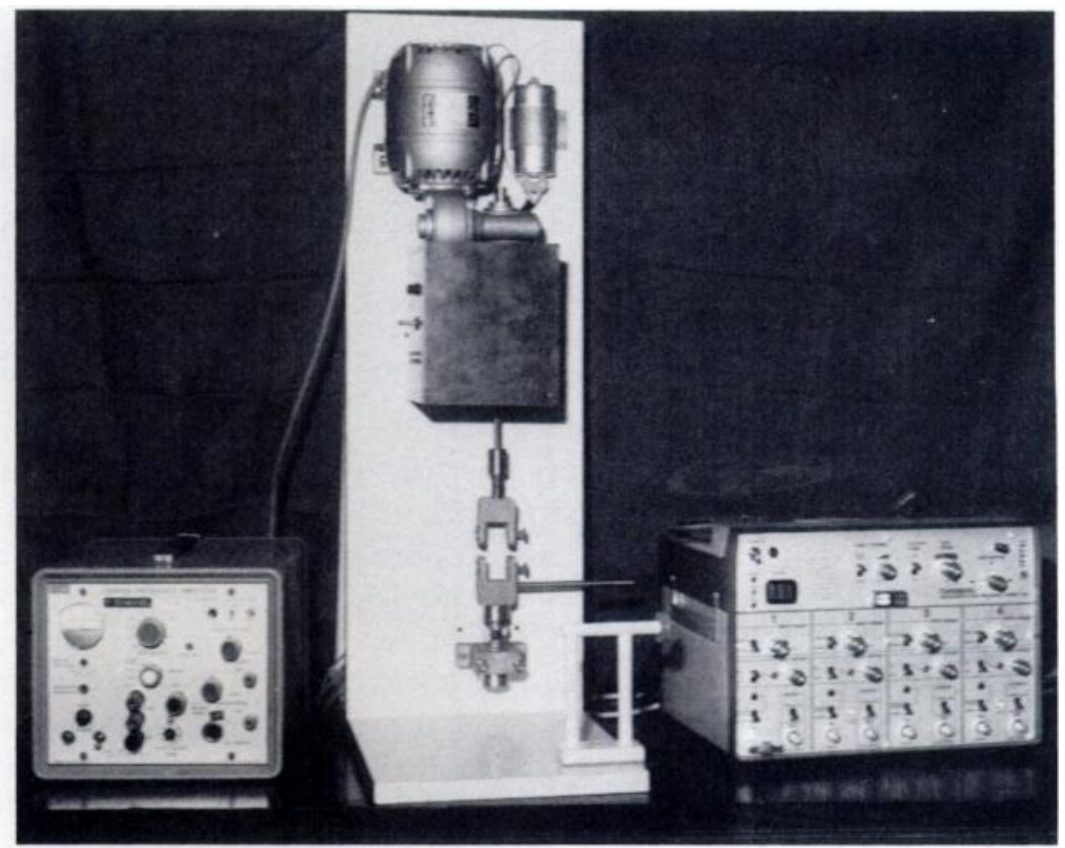

hormone given in widely differing doses, and that the fractures have usually been produced by digital methods which would be unlikely to give a satisfactorily uniform type of fracture. The assessment of fracture healing has also been carried out in many different ways, and the methods of mechanical testing have not been consistent. There therefore appeared to be good reason for the lack of uniformity in the results, and it was considered that another experiment, suitably designed, might produce unequivocal evidence of an acceleration of fracture healing by an adequate dose of growth hormone. For this reason the study described in this paper was carried out. As the recovery of mechanical strength is the main clinical requirement of the healing fracture, it was decided to concentrate entirely on testing such mechanical strength.

\section{MATERIALS AND METHODS}

Experimental animal. The Wistar rat was chosen as the experimental animal because it has a Haversian structure similar to that of human bone (Jowsey 1966) and because it has cross-species reactivity with bovine growth hormone. Sixty-five mature rats, weighing 300 to 400 grams, were used. They were kept under standard laboratory conditions.

Operation. Under clean conditions, with a non-touch technique, and using general anaesthesia by intraperitoneal pentobarbitone (Nembutal, 0.18 to 0.20 millilitre), a medial one-centimetre parapatellar incision was made, and the patella was dislocated laterally. The inferior part of the patellar groove was perforated with a twist drill, and a 0.035 -inch diameter Kirschner wire, held in a pin vice, was inserted into the femur until impaction in the trochanteric area was felt. The wire was then cut flush with the femoral condyles, and the patella relocated. The wound was closed with a Dexon suture, after instillation of topical antibiotics (Polybactrin). The procedure was then repeated on the other femur.

The experimental fracture. A closed transverse mid-shaft femoral fracture was produced using a three-point bending technique in a compressed-air driven press similar to that described by Jackson et al. (1970). The rat was positioned prone with its right hind leg held over the supports in full lateral rotation. The blunt central blade was then brought down to rest firmly on the anterior surface of the mid thigh, compressing the soft tissues, and the depth stop was adjusted to give a travel of two millimetres. With the release of the valve a pressure of 2.8 kilograms per square centimetre was applied to the piston driving the central blade, and the bone fractured with a just-audible click. A radiograph was then taken before recovery from anaesthesia, and if the fracture was unsatisfactory the animal was immediately killed. Fractures were only accepted if they were in the middle third, with minimal or absent comminution and a displacement of less than half the width of the shaft. Owing to the care taken to restrict the travel of the central blade, the displacement was actually less than one cortical thickness in 80 per cent of operations. When the radiograph was satisfactory, the animals were allowed to resume unrestricted activity in the cage on recovering from anaesthesia.

Administration of growth hormone. All animals were given daily intramuscular injections for five days a week starting on the second day after operation. The test animals were injected with five milligrams of bovine growth hormone (NIH-GH-B18) in one millilitre of buffered normal saline. The controls were injected with buffered normal saline only. The injections were rotated daily round the four quarters of each animal. The animals thrived and it was soon difficult to tell which leg had been fractured. They had usually recovered their pre-operative weight in one week and thereafter gained weight.

At two, three, four, five and seven weeks groups of controls were killed. The animals treated with growth hormone were killed in groups at two, three and four weeks, as preliminary work had suggested that the healing process was nearly complete at five weeks.

Mounting and testing of bones. After death, both femora of each rat were removed by sharp dissection and the Kirschner wires were extracted. The bones were then preserved at minus four degrees Celsius. Subsequently the bone ends were mounted in CMW acrylic cement to provide a rigid hold for torsional testing. After accidental disruption of some early soft unions, the jig was redesigned (Fig. 1), maintaining the same distance between the fixed parts of the bone. The sides of this jig could then be removed without the slightest stress being imparted to the site of the fracture.

The mounted femora were then tested in the specially designed torsional testing machine shown in Figure 2. A 200-watt electric motor was geared down to drive one end of the femur at a rate of 0.5 revolutions per minute. This drive, which had a vertical axis so as to eliminate the effect of gravity, was sufficiently powerful to overcome any resistance from the femur without change in speed. A strain gauge 
unit, mounted on the stationary side of the apparatus, gave an immediate read-out via a torque transducer onto a pen recorder and a similar permanent record on magnetic tape.

\section{ANALYSIS}

A typical torque-torsion curve is shown in Figure 3 . The horizontal axis represents torsion $(S)$ while the vertical axis represents torque $(T)$. An initial straight section corresponding to a primary phase of elastic deformation ends in a yield point marked by a change of slope. Beyond this point the curve rises gently, becoming gradually flatter as it reaches its peak, sometimes producing a variable plateau before falling to a final stage of failure.

Five measurements were taken from the curve for

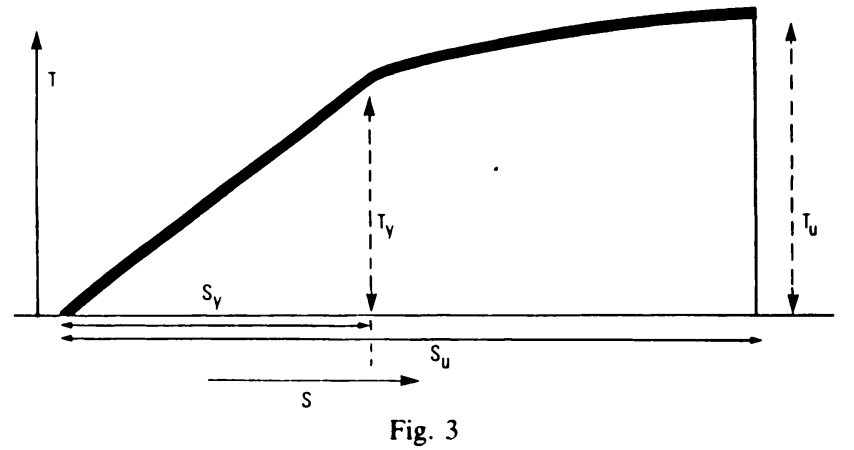

A typical torque-torsion curve and the measurements taken. $T$, torque; $S$, torsion. $T_{v}$, yield torque; $T_{u}$, ultimate torque.

each specimen. Three of these, all independent variables, were accurately measurable (Fig. 3). They were: the height of the peak of the curve, representing the ultimate torque $\left(T_{\mathrm{u}}\right)$ required to refracture the specimen; the horizontal distance to this peak, representing the angle through which the specimen had twisted to reach this point $\left(S_{\mathrm{u}}\right)$; the initial slope of the curve, representing the initial rigidity $(R)$ of the specimen. The other two measurements were based on the position of the yield point, and these were less precise. They were: the height of the curve at the yield point $\left(T_{y}\right)$, representing the torque required to take the specimen to its elastic limit; the horizontal distance to this point, representing the

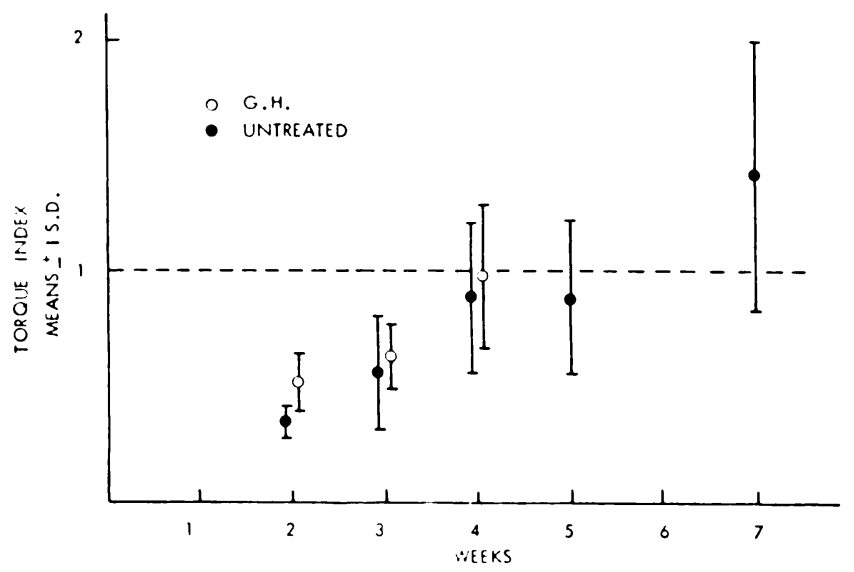

Fig. 4 angle of twist $\left(S_{y}\right)$ required. Only one of this latter pair, however, was a further truly independent variable, as the other measurement could be calculated using the equation

$$
\frac{T_{\mathrm{y}}}{S_{\mathrm{y}}}=R
$$

To reduce scatter because of changes in bone strength between individual rats, the strength of the healing fracture was in all cases compared with that of the opposite (normal) femur. Indices were thus defined as follows:

$$
\begin{aligned}
& \text { Torque index }=\frac{T_{\mathrm{u}} \text { on fractured side }}{T_{\mathrm{u}} \text { on normal side }} \\
& \text { Rigidity index }=\frac{R \text { on fractured side }}{R \text { on normal side }}
\end{aligned}
$$

Changes in these mechanical indices were studied.

\section{RESULTS}

Figures 4 and 5 show the changes in torque and rigidity indices with healing in controls and test animals.

Controls. The torque index rose steadily from less than one half at two weeks to more than unity at seven weeks. At two weeks the rigidity index was low and the fractures were easy to deform. At four weeks the rigidity of the fractured bones exceeded that of the normal bones. This finding will be discussed. In contrast with the torque index, the rigidity index had fallen to unity by seven weeks.

Test animals. In all three groups of test animals the mean torque indices were greater than in the controls, and the mean rigidity indices were lower than in the controls.

The greater torque index in the two-week group of test animals was statistically significant $(P=0.011)$ but the other differences were not. In particular when absolute values for $T_{u}$ only were considered, the differences between the controls and test animals ceased to be significant.

Yield point. With healing, the yield point moved along the torque-torsion curve from left to right. This is shown

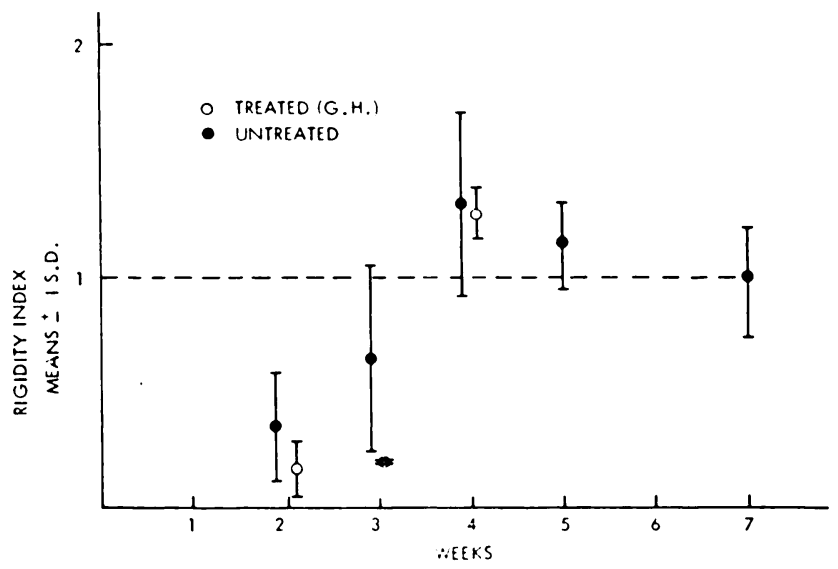

Fig. 5

Figure 4-Changes in torque index with healing. Figure $5-$ Changes in rigidity index with healing. 
Table I. Values of $S_{\mathrm{y}} / S_{\mathrm{u}}$ for experimentally fractured femora

\begin{tabular}{|l|c|c|}
\hline \multicolumn{1}{|c|}{ Group } & $\begin{array}{c}\text { Untreated } \\
\text { animals }\end{array}$ & $\begin{array}{c}\text { Treated (GH) } \\
\text { animals }\end{array}$ \\
\hline Two-week & 0.17 & 0.02 \\
Three-week & 0.62 & 0.72 \\
Four-week & 0.61 & 0.71 \\
Five-week & 0.80 & - \\
Seven-week & 0.88 & - \\
\hline
\end{tabular}

$\mathrm{GH}=$ Growth hormone

by the increasing values for $S_{\mathrm{y}} / S_{\mathrm{u}}$ in Table I. The differences between the groups of controls and test animals were again not significant.

\section{DISCUSSION}

The torque-torsion curves clearly demonstrated a biphasic property of fracture callus with a primary elastic phase and a secondary pseudo-plastic phase. This has previously been shown for three-point bending (Sarmiento et al. 1977) but not, so far as we are aware, for torsional testing. The latter system has the advantage of subjecting all the callus around the fracture to a shear stress. With three- or four-point bending, however, an unknown and probably variable amount of callus is subjected to compression while the remainder is in tension, and therefore a non-uniform force involving tension, compression and shear is applied across the callus. The movement of the yield point with healing showed clearly a gradual transition in the callus, from being mainly pseudo-plastic to mainly elastic and finally remaining elastic almost to the point of ultimate failure. Effects of growth hormone. Despite the lack of a statistically significant change in absolute values for ultimate torque $\left(T_{\mathrm{u}}\right)$, the increased torque index at two weeks at first appeared to be clear evidence that growth hormone had stimulated the early phases of fracture repair. It had been thought that if the hormone had any effect at all on the normal side this would be increased strength, as it is known to produce extensive new bone formation (Harris et al. 1972). In these circumstances a truly positive result would tend to be apparently diminished or masked (false negative) rather than mimicked (false positive). However, further analysis of the findings suggested the reverse, a tendency for growth hormone to cause a weakening of the opposite leg.

Table II shows the mean values of $T_{\mathrm{u}}$ for the normal femora in the controls and test animals. The mean strengths are seen to be lower in the latter throughout, though the differences are not statistically significant.

Table III shows the values of $S_{u}$ for the normal femora. In the two-week and four-week groups the torque resistance of the normal femur in the test animals began to fall off after a lesser angle of twist than that in the normal femur of the untreated animals. This was not
Table II. Values, in newton-metres, of $T_{\mathrm{u}}$ for normal (non-fractured) femora

\begin{tabular}{|l|c|c|c|c|c|}
\hline \multirow{2}{*}{\multicolumn{1}{|c|}{ Group }} & \multicolumn{2}{|c|}{ Untreated animals } & \multicolumn{2}{c|}{$\begin{array}{c}\text { Treated (GH) } \\
\text { animals }\end{array}$} & \\
\cline { 2 - 5 } & Mean & SD & Mean & SD & $P$ \\
\hline Two-week & 0.533 & 0.090 & 0.419 & 0.099 & NS \\
Three-week & 0.692 & 0.179 & 0.497 & 0.055 & NS \\
Four-week & 0.557 & 0.152 & 0.380 & 0.049 & NS \\
Five-week & 0.609 & 0.114 & - & - & \\
Seven-week & 0.552 & 0.207 & - & - & \\
\hline
\end{tabular}

$\mathrm{SD}=$ Standard deviation

NS $=$ Not significant

Table III. Values, in degrees, of $S_{\mathrm{u}}$ for normal (non-fractured) femora

\begin{tabular}{|c|c|c|c|c|c|}
\hline \multirow{2}{*}{ Group } & \multicolumn{2}{|c|}{ Untreated animals } & \multicolumn{2}{c|}{$\begin{array}{c}\text { Treated (GH) } \\
\text { animals }\end{array}$} & \multirow{2}{*}{} \\
\cline { 2 - 5 } & Mean & SD & Mean & SD & $P$ \\
\hline Two-week & 10.5 & 1.7 & 7.9 & 2.8 & NS \\
Three-week & 11.9 & 2.5 & 13.4 & 2.3 & NS \\
Four-week & 10.3 & 1.5 & 8.0 & 1.5 & $P<0.05$ \\
Five-week & 15.1 & 3.8 & - & - & - \\
Seven-week & 12.5 & 3.32 & - & - & - \\
\hline
\end{tabular}

the situation at three weeks, but re-examination of the specimens showed slight loosening in the fixation in some of the normal femora in the three-week group of test animals, giving an artificially high $S_{\mathrm{u}}$. There was no loosening, however, in the other groups, and the lower value of $S_{\mathrm{u}}$ in the four-week group of test animals was statistically significant, although only just so $(P<0.05)$. The femur on the normal side in test animals therefore tended to withstand a smaller torsion before ultimate failure and to fail at a lower load, and thus seemed to be more brittle. However, the changes seen were slight and might have been a chance finding. If these changes were a true effect of growth hormone, possibly owing to the large dose given, they would be consistent with the statement by Vaughan (1975) that in acromegalics there may be enlargement of Haversian canals and resorption cavities, with evidence of osteoporosis.

We cannot thus be certain about the meaning of the markedly increased torque index at two weeks in the animals treated with growth hormone. In the absence of a clear indication from the absolute values of whether this was due mainly to an increase in strength of the fractured side or a decrease in strength on the normal side, it seems likely that the finding was a combination of the two factors. An increase in strength on the fractured side would fit in well with the earlier work on the subject. The effect, however, is clearly rather small. 
Scatter in three-week group. Scatter has long been a problem in animal models of fracture repair. In this experiment the scatter in the healing fractures was greatest at three weeks. This is seen for example in Figure 5. There are two possible explanations. First, all the animals at two weeks and four weeks and some, including all the test animals, at three weeks were operated on and the fractures produced and tested by one of us (MDN-B); all the animals at five weeks and seven weeks and most of the untreated animals in the three-week group were operated on and the fractures produced and tested by another of us (MRW) at an earlier stage in the experiment. However, the animals came from one supplier and were of a similar weight and kept under identical conditions. Furthermore, close co-operation between the experimenters and subsequent perusal of all the radiographs did not disclose any significant differences in technique. Nevertheless this slight heterogeneity in the three-week group may possibly explain some of the wide scatter in that group.

There is, however, an attractive biological explanation based on non-linearity in fracture healing. Laurin,

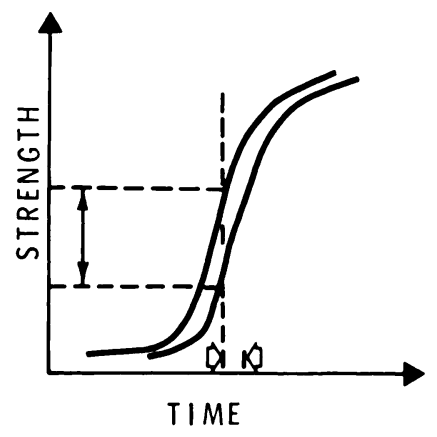

Fig. 6

Diagram which shows how a small change in the timing of a rapid increase in strength was likely to produce a wide variation in strength measurements taken during that rapid increase.

Sison and Roque (1963) investigated the rate of return of bending strength of the rabbit tibia after a standard osteotomy with a saw. In 164 fractures held with intramedullary pins they clearly demonstrated, with a sigmoid curve, a rapid recovery of strength at about three weeks. Figure 6 shows that a small difference in the timing of this rapid rise will produce a large change in strength, and thus measurements of strength are bound to show a wide variation if they coincide with this steep rise. That fractured bones in rats do not necessarily return to normal strength at a uniform rate was shown by Lindsay in 1934, although the shape of his curves was different. It is also interesting that Herbsman, Asrani and Shaftan (1966) showed a great increase in standard deviation in healing fractures of rat fibulae at this period. Rigidity at four weeks. The torsional rigidity $\left(T_{\mathrm{r}}\right)$ of a tube depends critically on its diameter $(D)$, with $T_{\mathrm{r}} \propto D^{4}$. A small increase in diameter thus produces a large increase in the torsional rigidity. This must also apply in the case of periosteal callus. Approximate measurements were made of the diameters using a Vernier scale, and at four weeks the healing femur was about twice the diameter of the normal femur; there was in fact little change in this discrepancy during the early stages of healing. It is thus not surprising that maturation of this wide-diameter tube of callus might produce a greater torsional rigidity (Fig. 5). In some cases there was sufficient rigidity for the bone to break through at a point other than the original site of fracture. With remodelling beyond the fourth week, the rigidity tended to fall to normal.

\section{CONCLUSIONS}

The results were consistent with earlier work showing a moderate stimulation by growth hormone, as measured by mechanical testing, of the earlier stages of fracture healing in the rat. There was no effect, however, after this early period and the results did not support the view that growth hormone given alone can produce an overall shortening of the process of healing. The histological changes reported by Koskinen (1959), which were in keeping with the well-known changes in epiphysial plate cartilage and with changes in articular cartilage noted by several authors (Silberberg, Silberberg and Hasler 1964; Chrisman and Leach 1971), may perhaps not persist beyond the early stages of healing in this experimental animal, or are not always present, or are not necessarily associated with increase in mechanical strength. The discovery (Salmon and Daughaday 1957) that growth hormone produces several effects via intermediary substances, the somatomedins, has complicated this subject still further. Growth hormone and a somatomedin, for example, may have opposite effects on the same organ, as demonstrated in a tissue culture of rat articular cartilage by Smith et al. (1975); and in dogs Mankin et al. (1978) found effects of growth hormone on cartilage opposite to those which were expected, with changes in bone showing that they were receiving adequate doses. It is perhaps not surprising that in the even more uncertain field of fracture healing the picture remains unclear. Overall, however, the results of the present study did strongly suggest that very little benefit, if any, is to be expected from the administration of growth hormone, at least when given alone, in the clinical treatment of fresh fractures.

We are particularly grateful to the following people for help with the design and construction of the bone breaking and testing equipment: the late Professor P. Ross. Dr Peter Beaumont, and Mr Derek Smith (Engineering Department, University of Cambridge), Dr David Jewett (Department of Medical Physics, Addenbrooke's Hospital), Mr R. V. Fabian and Mr Eric Bentley (Instrument Workshop, Addenbrooke's Hospital); to Dr Trevor Rae (Addenbrooke's Hospital) for help with statistics; and to the National Institute of Arthritis, Metabolism, and Digestive Disease (NIAMDD) who supplied the growth hormone from their Pituitary Hormone Distribution Programme. 


\section{REFERENCES}

Chrisman OD, Leach R. The effect of growth hormone and salicylate on established cartilage injuries. J Bone Joint Surg [Am] 1971:53-A:805.

Cordebar R, Guilleman P. L'action de l'hormone somatotrope sur la consolidation osseuse. Presse Med 1956;64:363-5.

Harris JM, Bean DA, Banks HH. Effect of phosphate supplementation, thyrocalcitonin, and growth hormone on strength of fracture healing. Surg Forum 1975;26:519-521.

Harris WH, Heaney RP, Jowsey J, Cockin J, Akins C, Graham J, Weinberg EH. Growth hormone: the effect on skeletal renewal in the adult dog. I. Morphometric studies. Calcif Tissue Res 1972;10:1-13.

Herbsman H, Asrani UF, Shaftan GW. An improved method for the evaluation of experimental fracture healing. Surg Forum 1966;17:447-9.

Jackson RW, Reed CA, Israel JA, Abou-Keer FK, Garside H. Production of a standard experimental fracture. Can J Surg 1970;13:415-20.

Jowsey J. Studies of Haversian systems in man and some animals. J Anat 1966;100,4:857-64.

Koskinen EVS. The repair of experimental fractures under the action of growth hormone, thyrotropin and cortisone. A tissue analytic, roentgenologic and autoradiographic study. Ann Chir Gynaecol Fenn 48 1959;Suppl 90.

Koskinen EVS. The effect of growth hormone and thyrotropin on human fracture healing: a clinical, quantitative, radiographic and metabolic study. Acta Orthop Scand 1963;Suppl 62.

Koskinen EVS, Nieminen RA, Lindholm RV, Puranen J, Attila U. Human growth hormone in bone regeneration of non-healing fractures. Calcif Tissue Res 1977;22:Suppl 521-3.

Laborit H, Favre A, Duchesne G, Dechen J, Bastit G. Essai d'utilisation d'une somatotrophine hypophysaire en pathologie générale étude biologique -indications, premiers resultats en therapeutique chirurgical. Presse Med 1953;61:1085-7.

Laurin CA, Sison V, Roque N. Mechanical investigation of experimental fractures. Can J Surg 1963;6:218-28.

Lindholm RV, Koskinen EVS, Puranen J, Nieminen RA, Kairaluoma M, Attila U. Human growth hormone in the treatment of fresh fractures. Horm Metab Res 1977;9:245-6.

Lindsay MK. Observations on fracture healing in rats. J Bone Joint Surg 1934;16:162-7.

Mankin HJ, Thrasher AZ, Weinberg EH, Harris WH. Dissociation between the effect of bovine growth hormone in articular cartilage and in bone of the adult dog. J Bone Joint Surg [Am] 1978;60-A:1071-5.

Salmon WD Jr, Daughaday WH. A hormonally controlled serum factor which stimulates sulfate incorporation by cartilage in vitro. $J$ Lab Clin Med 1957;49:825-36.

Sarmiento A, Schaeffer JF, Beckerman L, Latta LL, Enis JE. Fracture healing in rat femora as affected by functional weight-bearing.J Bone Joint Surg $[$ Am $]$ 1977;59-A:369-75.

Shepanek LA. The effect of endocrine substances (ACTH and growth hormone) on experimental fractures. Surg Gynecol Obstet 1953;96:200-4.

Silberberg M, Silberberg R, Hasler M. Ultrastructure of articular cartilage of mice treated with somatotrophin. J Bone Joint Surg [Am] 1964;46-A:766-80.

Smith TWD, Duckworth T, Bergenholtz A, Lemperg RK. Role of growth hormone in glycosaminoglycan synthesis by articular cartilage. Nature 1975;253:269-71.

Udupa KN, Gupta LP. The effect of growth hormone and thyroxine in healing of fracture. Indian J Med Res 1965;53:623-8.

Vaughan JM. The physiology of bone. 2nd ed. Oxford: Clarendon Press, 1975:222.

Wray JB, Goldstein J. The effect of the pituitary gland and growth hormone upon the strength of the healing fracture in the rat. J Bone Joint Surg $[A m]$ 1966;48-A:815-6.

Zadek RE, Robinson RA. The effect of growth hormone on healing of an experimental long-bone defect. J Bone Joint Surg [Am] $1961 ; 43-A: 1261$. 